Abstracta Iranica Abstracta Iranica

Revue bibliographique pour le domaine irano-aryen

Volume 40-41 | 2019

Comptes rendus des publications de 2017-2018

Claudia Leurini. Hymns in Honour of the Hierarchy and Community, Installation Hymns and Hymns in Honour of Church Leaders and Patrons. Middle Persian and Parthian Hymns in the Berlin Turfan Collection

\title{
Samra Azarnouche
}

\section{OpenEdition}

Journals

Édition électronique

URL : http://journals.openedition.org/abstractairanica/50878

DOI : $10.4000 / a b s t r a c t a i r a n i c a .50878$

ISBN : 1961-960X

ISSN : 1961-960X

Éditeur :

CNRS (UMR 7528 Mondes iraniens et indiens), Éditions de l'IFRI

\section{Référence électronique}

Samra Azarnouche, « Claudia Leurini. Hymns in Honour of the Hierarchy and Community, Installation Hymns and Hymns in Honour of Church Leaders and Patrons. Middle Persian and Parthian Hymns in the Berlin Turfan Collection », Abstracta Iranica [En ligne], Volume 40-41 | 2019, document 2, mis en ligne le 30 décembre 2019, consulté le 24 avril 2021. URL : http://journals.openedition.org/abstractairanica/ 50878 ; DOI : https://doi.org/10.4000/abstractairanica.50878

Ce document a été généré automatiquement le 24 avril 2021.

Tous droits réservés 
Claudia Leurini. Hymns in Honour of the Hierarchy and Community, Installation Hymns and Hymns in Honour of Church Leaders and Patrons. Middle Persian and Parthian Hymns in the Berlin Turfan Collection

\author{
Samra Azarnouche
}

\title{
RÉFÉRENCE
}

Claudia Leurini. Hymns in Honour of the Hierarchy and Community, Installation Hymns and Hymns in Honour of Church Leaders and Patrons. Middle Persian and Parthian Hymns in the Berlin Turfan Collection. Berliner Turfantexte XL, Brepols, Turnhout, 2017, 214 p., 4 planches. ISBN 978- 2-503-57550-6

1 L'ouvrage représente un travail philologique de qualité, dans la continuité des travaux initiés dans la collection berlinoise par Werner Sundermann. Les hymnes manichéens moyen-perses et parthes analysés dans ce recueil avaient pour la plupart été édités par Mary Boyce dans son catalogue de 1960 ( ${ }^{\circ} 73$ sur la hiérarchie de l'église manichéenne et $n^{\circ} 75$ contenant des hymnes d'installation et ceux en l'honneur des chefs de l'église). Des éléments fort utiles sur les traditions scripturaires, notamment des exemples de « cryptographie » (des messages cachés ou des mots formés par les initiales d'une série de mots) ou des données sur la transmission des compétences des scribes (p. 23-26) apportent un éclairage sur le contexte culturel de la production des documents.

2 Après une introduction (p. 1-26) décrivant avec précision la titulature des chefs de l'église manichéenne (par ex. bay, sārār, šahryār, wispuhr etc.), la première partie se 
consacre aux hymnes dédiés à la hiérarchie de l'église, p. 27-64 : M11, M36, M192, M202, M241/R/, M626, M6604/R/, M1145/B/+M1147/B/, M37/II, III 8259, M5848, un hymnes dédié aux Auditeurs, III 36, et deux autres dédiés à l'église, M190/A/ et M5680.

3 La seconde partie traite des hymnes d'installation et des hymnes en l'honneur du clergé et des patrons, p. 65-160 : M729, M223/I, M291c, M339, M460a, M797/I, M871n, M1863, M436, M297/A/, M543 (dédié sans doute au chef de la communauté des Dēnāwarìya), M7351/R, M7860/R/, M1952, M5261, M7250, à l'installation des maitres : M31/I/V/, M661, M873c, M639a-b, à l'installation des évêques : M31/II, M871e, à l'installation des prêtres : M587, des éloges aux chefs de l'église : M31/I/R/, M277, III 4974, 1108/R/H/, M37/I, M74/I, M276, M293, M190/B/, M586, M391, M1062, M3846, M6665 (où le maître est désigné comme sarhang "leader »), des hymnes dédiés aux maitres : M 59/I, un roi ouïgour du clan Yaghlakar, Tänri Han Köl Bilgä Khagan, qui permet de dater le fragment de 744 à 747 de notre ère : M43, M 1367/V/, M297/B/.

4 La troisième partie rassemble des hymnes d'attribution incertaine, très fragmentaires, p. 161-169: M8533/V/+M5436/I/V/, M494, M5220, M6955, M1366, M858b, M6604/V/, M6664-.

5 Chaque hymne est précédé de l'historique complet des travaux antérieurs ainsi que de considérations d'ordre codicologique. Le texte transcrit et traduit en anglais est tantôt disposé en deux colonnes en regard, tantôt en deux parties successives, la traduction suivant le texte original qui respecte sa disposition sur le document. Un lecteur non averti pourrait être freiné par l'absence de toute transcription, y compris dans le glossaire. Des commentaires philologiques très détaillés suivent chaque hymne. Les lectures alternatives et les observations paléographiques sont reléguées à des notes infrapaginales.

6 Le glossaire (p. 171-196) renvoie aux numéros de ligne où figure chaque lemme. Après une bibliographie (p. 197-211), quatre planches en couleur achèvent le volume.

\section{AUTEURS}

\section{SAMRA AZARNOUCHE}

EPHE, Mondes iranien et indien, Paris 